TPBIO (Jurnal Pendidikan Biologi)
Vol. 5, No. I, April 2020,96 - I05//e-ISSN 2540-802X
http://jurnal.stkippersada.ac.id/jurnal/index.php/JBIO/index

\title{
Etnobotani: tumbuhan ritual keagamaan hindu-bali
}

\section{Rizhal Hendi Ristanto, Ade Suryanda, Ade Imas Rismayati, Aty Rimadana, Rahmirini Datau}

Pendidikan Biologi, Fakultas MIPA, Universitas Negeri Jakarta, Jl. Rawamangun Muka, DKI Jakarta (I3220), Jakarta Timur, Indonesia,

Korespondensi penulis: rizhalhendi@unj.ac.id

Informasi artikel

Riwayat artikel:

Dikirim 23 Februari 2020

Direvisi 04 Maret 2020

Diterima 03 April 2020

Dipublikasi 07 April 2020

Kata kunci:

Etnobotani, Hindu-Bali, tumbuhan ritual

\section{ABSTRAK}

Pulau Bali dikenal sebagai pulau seribu pura dengan mayoritas penduduk beragama Hindu menggunakan tumbuhan dalam kegiatan ritual keagamaan Hindu-Bali. Penelitian ini bertujuan untuk mengetahui macam-macam tumbuhan ritual keagamaan Hindu-Bali. Penelitian ini terkait etnobotani yang dilaksanakan pada bulan April tahun 2018 pada tiga lokasi yaitu kebun raya Bali, taman wisata alam Danau Buyan, dan Pura Ulun Danu Beratan, Kabupaten Tabanan dan Buleleng, Bali. Data dikumpulkan melalui teknik wawancara, observasi, dan studi pustaka. Narasumber ditentukan dengan teknik purposive sampling dan simple random sampling. Analisis data dilakukan melalui deskriptif kualitatif. Hasil penelitian ditemukan terdapat IOI spesies tumbuhan yang digunakan dalam ritual keagamaan Hindu-Bali. Bagian umbi II spesies, bagian batang I0 spesies, bagian biji 5 spesies, bagian daun 29 spesies, bagian bunga 17 spesies, bagian buah 9 spesies, dan bagian kulit batang 20 spesies. Mayarakat Hindu-Bali mempercayai bahwa suatu warna melambangkan dewa, yaitu kuning melambangkan Mahadewa, hitam melambangkan Dewa Wisnu, putih melambangkan Dewa Shiwa, dan merah melambangkan dewa Brahma.

Keywords:
Ethnobotany, Hindu Bali, ritual
plants
plants

\section{ABSTRACT}

Etnobotani: hindu-bali religious ritual plant. Bali Island is known as the Thousand Pura Island with a Hindu population used in Hindu-Balinese religious ritual activities. The study of botany relating to the culture of society is called Ethnobotany. Types of Hindu-Balinese religious rituals. The study was conducted in April 2018 at three locations in the Bali Botanic Garden, Danau Buyan Nature Park, and Ulun Danu Beratan Temple, Tabanan and Buleleng regency, Bali Province. Data collected through interview techniques, observation, and literature study. The informants were determined by purposive sampling and simple random sampling techniques. Data analysis was performed through descriptive qualitative. The results found IOI species of plants used in Hindu-Balinese religious rituals. Tuber parts II species, IO stem species, 20 bark species, 29 leaf species, I7 flower species, 9 fruit species, and 5 species seeds. Hindu-Balinese people believe that one of the colors symbolizes deity, namely yellow symbolizes Mahadeva, black symbolizes Lord Vishnu, white symbolizes Lord Shiva, and red symbolizes the Brahma.

(C) 2020 Ristanto et al

This is an open access article under the CC-BY-SA license

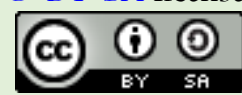

Sitasi: Ristanto, R.H., Suryanda, A., Rismayati, A.I., Rimadana, A., \& Datau, R. (2020). Etnobotani: tumbuhan ritual keagamaan hindu-bali. JPBIO (Jurnal Pendidikan Biologi), 5(I), 96-I05. DOI: I0.31932/jpbio.v5iI.642 


\section{PENDAHULUAN}

Tumbuhan dapat digunakan berbagai keperluan dalam menjalankan ritual keagamaan (Sharma \& Pegu, 20I I). Pulau Bali merupakan daerah mayoritas penduduknya beragama Hindu (Saleh, 2017). Agama Hindu Bali berkaitan erat dengan kegiatan upakara keagamaan. Kegiatan tersebut ditemukan hampir sepanjang tahun mulai dari ritual harian, bulanan, tahunan, puluhan tahun dan bahkan ratusan tahun (Ayadnya \& Arinasa, 2004). Masyarakat Bali mayoritas menganut agama Hindu, konsep dasar ajaran agama Hindu adalah memanusiakan alam dan lingkungan (Winarsih, 2015). Pelaksanaan dari konsep tersebut dilakukan melalui aktifitas upacara keagamaan. Ritual tersebut mengandung makna atau pesan kepada umat yaitu rasa takut, ketundukan dan kesucian terhadap Tuhan Yang Maha Esa.

Ritual keagamaan merupakan kegiatan yang wajib dilakukan oleh setiap penganut suatu agama. Masyarakat Bali dikenal taat beribadah, berbagai macam prosesi ritual keagamaan dilakukan oleh masyarakat Bali. Salah satu ritual keagamaan yaitu dengan memanfaatkan berhubungan tumbuhan dalam prosesi ritual keagamaan Hindu-Bali (Nasution et al., 2018). Studi tentang botani (tumbuhan) yang berhubungan dengan budaya masyarakat disebut etnobotani (Mesfin et al., 2013).

Menurut Ginting (2012) dan Winarsih (2015) etnobotani berasal dari kata etnologi dan botani. Etnologi adalah kajian mengenai budaya, dan botani adalah kajian mengenai tumbuhan, jadi etnobotani adalah suatu bidang ilmu yang mempelajari hubungan antara manusia dan tumbuhan. Selanjutnya, menurut Hidayat et al., (2010) etnobotani merupakan ilmu yang mengkaji hubungan langsung manusia dengan tumbuhan dalam pemanfaatan secara tradisional, dan menurut Choudhary et al. (2008) focus etnobotani adalah bagaimana pemanfaatan tumbuhan pada proses ritual. Kajian mengenai etnobotani ini dapat dijadikan sebagai dasar pelaksanaan kebudayaan yang berkaitan dengan ritual keagamaan. Upacara keagamaan merupakan kegiatan yang wajib dilakukan oleh setiap penganut suatu agama.

Tumbuhan dalam kehidupan masyarakat Bali mempunyai arti penting karena banyak jenis tumbuhan yang dimanfaatkan dalam berbagai kegiatan upacara keagamaan (Ambarani, 2016). Tumbuhan tersebut merupakan salah satu perlengkapan bahan upacara yang disebut sebagai upakara atau banten yang berupa daun, buah dan bunga (Suryadarma, 2008; Lestari, 2004). Jumlah tumbuhan yang digunakan dalam kegiatan upacara tersebut banyak dan beragam serta memiliki makna yang mungkin berbeda antara satu dengan yang lainnya (Putri et al., 20I4).

Tumbuhan tradisional Bali mempunyai filosofi yang sangat tinggi sebagai unsur yang memberi kehidupan, keteduhan, kedamaian, keindahan, tempat meditasi, memuji dan menyembah kebesaran Tuhan sebagai warisan budaya Hindu di Bali (Iskandar, 2016). Hal tersebut membuat pulau Dewata Bali menjadi salah satu tempat yang menarik untuk dijadikan sebagai tempat penelitian mengenai studi etnobotani. Penelitian dengan kajian etnis di Indonesia telah banyak dilakukan Harahap et al. (2009) mengkaji terkait penggunaan tumbuhan yang digunakan untuk pengobatan hewan ternak. Sholichah \& Alfidhdhoh, (2020) mengkaji terkait tumbuhan liar sebagai pangan masyarakat di Jombang.

Kajian tentang tumbuhan sebagai sarana ibadah di Bali telah dilakukan oleh Sujarwo \& Lestari (2019). Namun penelitian etnobotani di Bali belum mengungkap jenis tumbuhan oleh masyarakat di sekitar kebun raya Bali, taman wisata alam danau Buyan, dan Pura Ulun Danu Beratan, kabupaten Tabanan dan kabupaten Buleleng, provinsi Bali. Penelitian menrujuk terhadap penelitian sebelumnya oleh Sharma \& Pegu (20I I) mengkaji tentang tumbuhan yang dipercaya di India. Berdasarkan kajian tersebut, maka penelitian ini bertujuan untuk mengetahui jenis dan pemanfaatan tumbuhan dalam ritual keagamaan Hindu-Bali.

\section{METODE PENELITIAN}

\section{Rancangan Penelitian}

Penelitian ini merupakan penelitian deskriptif kualitatif dengan teknik survei. Penelitian dilakukan pada bulan April 2018 di kebun raya Bali, taman wisata alam danau Buyan, dan Pura Ulun Danu Beratan, kabupaten Tabanan dan kabupaten Buleleng, provinsi Bali yang terlihat pada Gambar I. Alat yang digunakan meliputi alat tulis, kamera DSLR, handycam, instrumen wawancara dan buku panduan mofologi tumbuhan (Steenis, 2008; Tjitrosoepomo, 20I8). Bahan yang dibutuhkan yaitu berbagai jenis tumbuhan yang digunakan dalam ritual keagamaan Hindu-Bali yang ditemukan pada saat penelitian. 


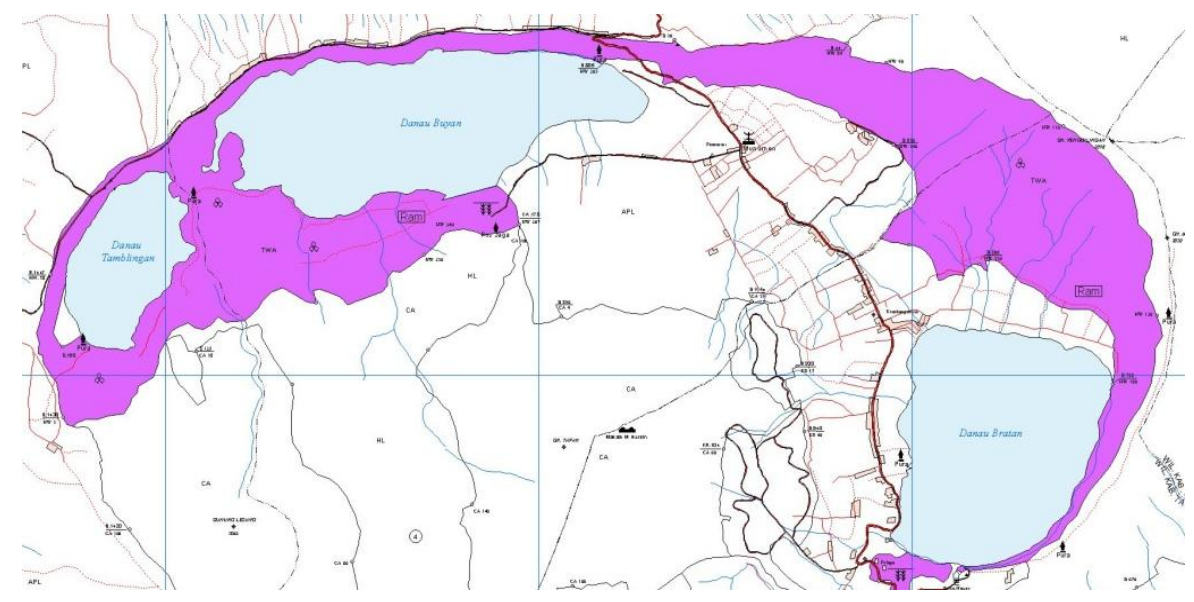

Gambar 1. Peta lokasi penelitian

\section{Responden}

Pemilihan responden dilakukan melalui teknik purposive, yaitu dengan metode targeted respondents. Beberapa responden yang dipilih dalam penelitian ini yaitu ahli etnobotani di kebun raya Bali, dua pemuka agama (pendeta) dan tiga masyarakat Hindu-Bali di sekitar taman Nasional Bali-Barat.

\section{Instrumen Penelitian}

Instrumen penelitian yang digunakan adalah daftar pertanyaan terkait jenis tumbuhan yang digunakan dalam kegiatan sarana upakara. Kriteria responden dalam penelitian ini adalah ahli etnobotani yang memiliki pengalaman terkait penggunaan tumbuhan acara keagamaan, pemuka agama dan masyarakat yang memeluk agama Hindu dan sering melakukan ritual keagamaan. Daftar pertanyaan yang berikan kepada responden terdapat pada Tabel I.

Tabel I. Instrumen pengumpulan data

\begin{tabular}{cl}
\hline Kode Pertanyaan & \multicolumn{1}{c}{ Pertanyaan } \\
\hline Q1 & $\begin{array}{l}\text { Bali merupakan wilayah yang mayoritas beragaman Hindu dan tidak terlepas dengan } \\
\text { ritual keagamaannya, apa saja jenis ritual keagamaan Hindu-Bali? }\end{array}$ \\
\hline Q2 & Pada pelaksanaan ritual keagamaan Hindu-Bali, jenis tumbuhan apa saja yang digunakan? \\
\hline Q3 & Apa nama lokal tumbuhan yang digunakan dalam ritual keagamaan Hindu-Bali? \\
\hline Q4 & $\begin{array}{l}\text { Tumbuhan terdiri dari beberapa bagian organ, seperti akar, batang, daun, bunga, buah } \\
\text { dan biji, lalu bagian tumbuhan apa yang digunakan dalam ritual keagamaan Hindu-Bali? }\end{array}$ \\
\hline Q5 & Apa alasan digunakannya tumbuhan tersebut dalam ritual keagamaan Hindu-Bali? \\
\hline Q6 & $\begin{array}{l}\text { Bagaimana karakteristik morfologi tumbuhan yang digunakan dalam ritual keagamaan } \\
\text { Hindu-Bali? }\end{array}$ \\
\hline Q7 & Apa fungsi tumbuhan tersebut dalam ritual keagamaan Hindu-Bali? \\
\hline Q9 & Apakah tumbuhan tersebut dapat digantikan oleh jenis tumbuhan yang lainnya? \\
\hline Q10 & $\begin{array}{l}\text { Apakah tumbuhan tersebut dibudidayakan oleh masyarakat Bali? } \\
\text { Hindu-Bali? }\end{array}$ \\
\hline Q1 & Tumbuhan apakah yang selalu ada dalam setiap ritual keagamaan Hindu-Bali? \\
\hline
\end{tabular}

\section{Prosedur Penelitian}

Pengambilan sampel penelitian dilakukan dengan teknik purposive sampling dan simple random sampling. Data dikumpulkan melalui teknik wawancara semi-terstuktur (semi-structured interview), observasi lapangan, dan studi pustaka. Wawancara yang dilakukan berupa penggaliaan informasi terkait pemanfaatan tumbuhan sebagai sarana upakara dalam ritual keagamaan Hindu-Bali yang meliputi nama tumbuhan, bagian tumbuhan yang digunakan, dan alasan pemilihan tumbuhan. Selanjutnya dilakukan observasi lapangan di taman 
Panca Yadnya yang terletak di dalam kawasan kebun raya Bali. Setelah itu, dilakukan pula studi pustaka untuk memverifikasi data yang diperoleh dari hasil wawancara dan observasi.

\section{Teknik Analisis Data}

Analisis data pada penelitian ini menggunakan analisis deskriptif kualitatif. Teknik pengumpulan data dengan wawancara dan observasi non-partisipan. Analisis ini merupakan analisis isi (content analysis) berdasarkan data mengenai pengetahuan responden terhadap tumbuhan yang digunakan dalam ritual keagamaan Hindu-Bali.

\section{HASIL PENELITIAN}

Berdasarkan penelitian di Bedugul Bali, terdapat IOI jenis tumbuhan yang digunakan sebagai sarana upakara dalam kegiatan ritual keagamaan oleh masyarakat Hindu-Bali. Hasil Penelitian menunjukkan bahwa jumlah jenis tanaman bagian umbi yang digunakan untuk ritual keagamaan Hindu-Bali adalah II spesies (Tabel 2), bagian batang 10 spesies (Tabel 3), bagian biji 5 spesies (Tabel 4), bagian daun 29 spesies (Tabel 5), bagian bunga I7 spesies (Tabel 6), bagian buah 9 spesies (Tabel 7), dan bagian kulit batang 20 spesies (Tabel 8),

Tabel 2. Jumlah dan jenis tumbuhan yang menggunakan bagian umbi untuk ritual keagamaan Hindu-Bali

\begin{tabular}{cll}
\hline No. & Jenis Tumbuhan/Nama Ilmiah & Bagian tumbuhan yang digunakan \\
\hline I & Caladium bicolor & \\
\hline 2 & Ipomoea batata & \\
\hline 3 & Curcumasp sp. & \\
\hline 4 & Curcuma purpurascens & Umbi \\
\hline 5 & Curcuma aeruginosa & \\
\hline 6 & Curcuma xanthorrhizae & \\
\hline 7 & Boesenbergia pandurata & \\
\hline 8 & Allium cepa \\
\hline 9 & Alium sativum \\
\hline I0 & Curcuma domestica \\
\hline I I & Kaempferia galangal \\
\hline Jumlah & II spesies &
\end{tabular}

Tabel 3. Jumlah dan jenis tumbuhan yang menggunakan bagian batang untuk ritual keagamaan Hindu-Bali

\begin{tabular}{cll}
\hline No. & Jenis Tumbuhan/Nama Ilmiah & Bagian tumbuhan yang digunakan \\
\hline I & Saccharum sp. & \\
\hline 2 & Saccharum officinarum & \\
\hline 3 & Musa sp. & \\
\hline 4 & Lycopodium cernuum & Batang \\
\hline 5 & Cynodon dactylon & \\
\hline 6 & Leonurus sibiricus & \\
\hline 7 & Padang kasna & \\
\hline 8 & Schefflera elliptica & \\
\hline 9 & Citrus aurantifolia & \\
\hline I0 & Arenga pinnata & \\
\hline Jumlah & I0 spesies &
\end{tabular}

Tabel 4. Jumlah dan jenis tumbuhan yang menggunakan bagian biji untuk ritual keagamaan Hindu-Bali

\begin{tabular}{cll}
\hline No. & Jenis Tumbuhan/Nama Ilmiah & Bagian tumbuhan yang digunakan \\
\hline I & Vigna sinensis & \\
\hline 2 & Mucuna pruriens & Biji \\
\hline 3 & Cajanus cajan & \\
\hline 4 & Glycine max & \\
\hline 5 & Oryza sativa & \\
\hline Jumlah & 5 spesies &
\end{tabular}


Tabel 5. Jumlah dan jenis tumbuhan yang menggunakan bagian daun untuk ritual keagamaan Hindu-Bali

\begin{tabular}{cl}
\hline No. & Jenis Tumbuhan/Nama Ilmiah \\
\hline I & Piperbetle sp. \\
\hline 2 & Pleomele angustifolia \\
\hline 3 & Oryza sativa \\
\hline 4 & Azadirachta indica \\
\hline 5 & Medinella speciosa \\
\hline 6 & Coryiline fruticosa \\
\hline 7 & Artocarpus integra \\
\hline 8 & Musa paradisiaca \\
\hline 9 & Hibiscus rosa-sinensis \\
\hline I0 & Cocos nucifera L. \\
\hline I & Codiaeum variegatum \\
\hline I2 & Pandanus amaryllifolius \\
\hline I3 & Phyllanthus buxifolius \\
\hline I4 & Ficus benjamina \\
\hline I5 & Imperata cylindrica \\
\hline I6 & Musa sp. \\
\hline I7 & Alpinia galanga \\
\hline I8 & Zingiber purpureum \\
\hline I9 & Zingiber americans \\
\hline 20 & Zingiber officinale \\
\hline 21 & Piper nigruum \\
\hline 22 & Sesamu mindicum \\
\hline 23 & Lycopodium cernuum \\
\hline 24 & Cynodon dactylon \\
\hline 25 & Leonurus sibiricus \\
\hline 26 & Padang kasna \\
\hline 27 & Schefflera elliptica \\
\hline 28 & Citrus aurantifolia \\
\hline Jumlah & Arenga pinnata \\
\hline &
\end{tabular}

Tabel 6. Jumlah dan jenis tumbuhan yang menggunakan bagian bunga untuk ritual keagamaan Hindu-Bali

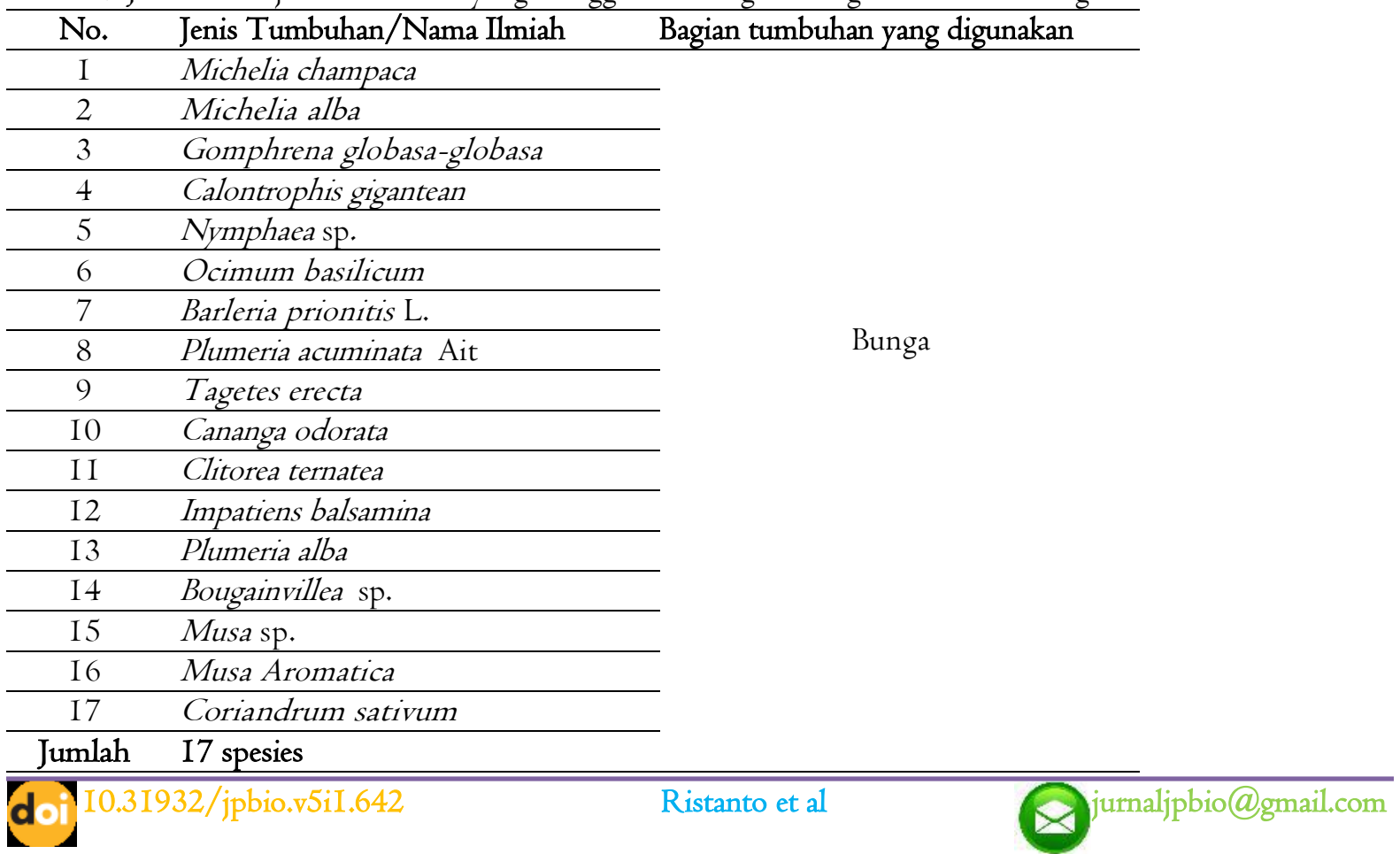


Tabel 7. Jumlah dan jenis tumbuhan yang menggunakan bagian buah untuk ritual keagamaan Hindu-Bali

\begin{tabular}{cll}
\hline No. & Jenis Tumbuhan/Nama Ilmiah & Bagian tumbuhan yang digunakan \\
\hline I & Cucumis sativus & \\
\hline 2 & Momordi- cacharantia & \\
\hline 3 & Beninca sahispida & \\
\hline 4 & Cucurbita moschata & Buah \\
\hline 5 & Areca catechu & \\
\hline 6 & Musa sp. & \\
\hline 7 & Capsicum anuum & \\
\hline 8 & Cocos nucifera L. & \\
\hline 9 & Eugenia aromatic & \\
\hline Jumlah & 9 spesies &
\end{tabular}

Tabel 8. Jumlah dan jenis tumbuhan yang menggunakan bagian batang dan kulit untuk ritual keagamaan Hindu-Bali

\begin{tabular}{cl}
\hline No. & Jenis Tumbuhan/Nama Ilmiah \\
\hline I & Ficus benjamina \\
\hline 2 & Alstonia scholaris R.Br. \\
\hline 3 & Cinnamo muminers Reinw. \\
\hline 4 & Ficus rumphii. Bl. \\
\hline 5 & Erythrina variegate \\
\hline 6 & Sukasti sp. \\
\hline 7 & Casuarina equisetifolia $\mathrm{L}$. \\
\hline 8 & Azadirachta indica \\
\hline 9 & Messua ferrea Lin. \\
\hline I0 & Phyllanthus buxifolius \\
\hline I I & Leea aquleata \\
\hline I2 & Aleurites moluccana \\
\hline I3 & Myristica fragrans \\
\hline I4 & Moringa oliefera \\
\hline I5 & Schefflera eliptica \\
\hline I6 & Ceiba petandra L. \\
\hline I7 & Santalum album L. \\
\hline I8 & Cananga odorata \\
\hline I9 & Dysoxylum caulostachyum batang \\
\hline 20 & Bambusa vulgaris \\
\hline Jumlah & 20 spesies \\
\hline
\end{tabular}

\section{PEMBAHASAN}

Bali merupakan salah satu pulau di Indonesia yang dikenal dengan sebutan Pulau Dewata (Malik, 2016; Peneng, \& Sumantera, 2005). Masyarakat lokal dan internasional berkunjung ke Bali karena kearifan lokal yang dimiliki oleh Pulau Dewata tersebut. Masyarakat Bali mayoritas beragama Hindu, upacara keagamaan masyarakat Hindu-Bali sudah menjadi budaya tersendiri yang menjadi salah satu pembeda pulau Dewata Bali dengan daerah yang lainnya. Pelaksanaan ritual keagamaan Hindu-Bali selalu memanfaatkan tumbuhan untuk melengkapi upacara tersebut (Dharma et al., 2002). Tumbuhan memiliki berbagai manfaat dalam kehidupan manusia (Lestari et al., 2019a; 2019b), diantaranya yaitu dimanfaatkan dalam kegiatan ritual, adat dan keagamaan (Hidayat et al., 2010). Pemanfaatan jenis-jenis tumbuhan dalam upacara memberi amanat atau pesan tanggungjawab atas pelestarian tumbuh-tumbuhan, agar pelaksanaan upacara bisa terus berlangsung (Nasution et al., 2018). Interaksi antara masyarakat dengan tumbuhan yang digunakan dalam pelaksanaan ritual keagamaan disebut dengan etnobotani (Martin, 1998; Dharmono, 2007; Hidayat et al., 2010). Etnobotani sebagai disiplin ilmiah belum banyak dikembangkan di Indonesia (Iskandar, 2016). Etnobotani adalah studi tentang hubungan antara tumbuhan dan manusia serta tentang bagaimana berbagai budaya menggunakan tumbuhan, salah satunya dalam upacara ritual keagamaan (Babaian \& Twigg, 20I I). Kajian etnobotani mampu meningkatkan sensitivitas 
masyarakat terhadap tumbuhan yang ada disekitar lingkungan mereka, bahwa tumbuhan memiliki peran penting dalam berbagai segi kehidupan, salah satunya dalam pelaksanaan ritual keagamaan (Babaian, 20II).

Berdasarkan hasil penelitian yang dilakukan, diketahui bahwa di Bedugul Bali secara umum terdapat IOI spesies tumbuhan yang digunakan dalam ritual keagamaan Hindu-Bali. Data menunjukkan bahwa masyarakat Hindu-Bali menggunakan tumbuhan tersebut berdasarkan pada kepercayaan masyarakat terhadap tumbuhan tertentu yang digunakan dalam pelaksanaan ritual keagamaan yang dilakukan secara turun temurun.

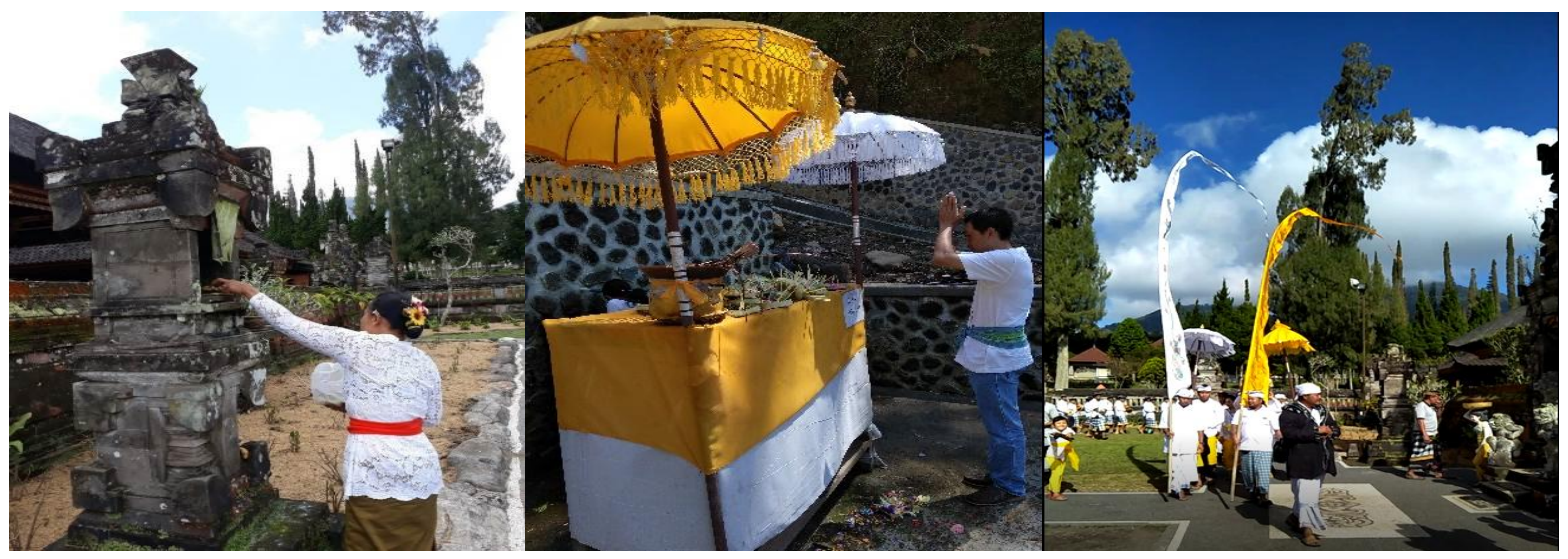

Gambar 2. Pelaksanaan upacara ritual keagamaan.

Pelaksanaan upacara ritual keagamaan Hindu-Bali selalu memanfaatkan tumbuhan (Lestari, 2004; Surata et al., 2015), namun tidak terdapat tumbuhan khusus yang wajib ada maupun karakter morfologi khusus yang digunakan. Ritual upakara keagaamaan terdapat pada Gambar 2. Diantara spesies-spesies tumbuhan yang digunakan dalam ritual keagamaan Hindu-Bali, banyak di antaranya merupakan tumbuhan berbunga menarik dan bagian tumbuhan yang paling sering digunakan adalah bunga. Dalam agama Hindu, bunga dengan berbagai macam warna memiliki fungsi sebagai simbol kehidupan (sthiti) (Nala, 2004), sehingga karakter warna menjadi acuan dalam pemilihan tumbuhan yang digunakan. Bunga yang digunakan tidak spesifik, melainkan dapat digantikan oleh bunga atau bagian tumbuhan lainnya yang memiliki warna sama. Mayarakat Hindu-Bali mempercayai bahwa suatu warna melambangkan dewa mereka, yaitu bunga warna kuning melambangkan Mahadewa, hitam melambangkan Dewa Wisnu, putih melambangkan Dewa Shiwa, dan merah melambangkan Dewa Brahma (Sudarsana, 2010). Selain bunga, bagian tumbuhan lain yang digunakan dalam ritual keagamaan Hindu-Bali adalah daun, umbi, batang atau kulit batang, buah, dan biji. Bagian tumbuhan tersebut digunakan sebagai pelengkap dalam ritual keagamaan Hindu-Bali, yaitu sebagai sarana upakara atau banten yang biasanya dirangkai dalam bentuk canang. Macam-macam canang antara lain yaitu canang raka, canang genten, dan canang sari (Gambar 3).

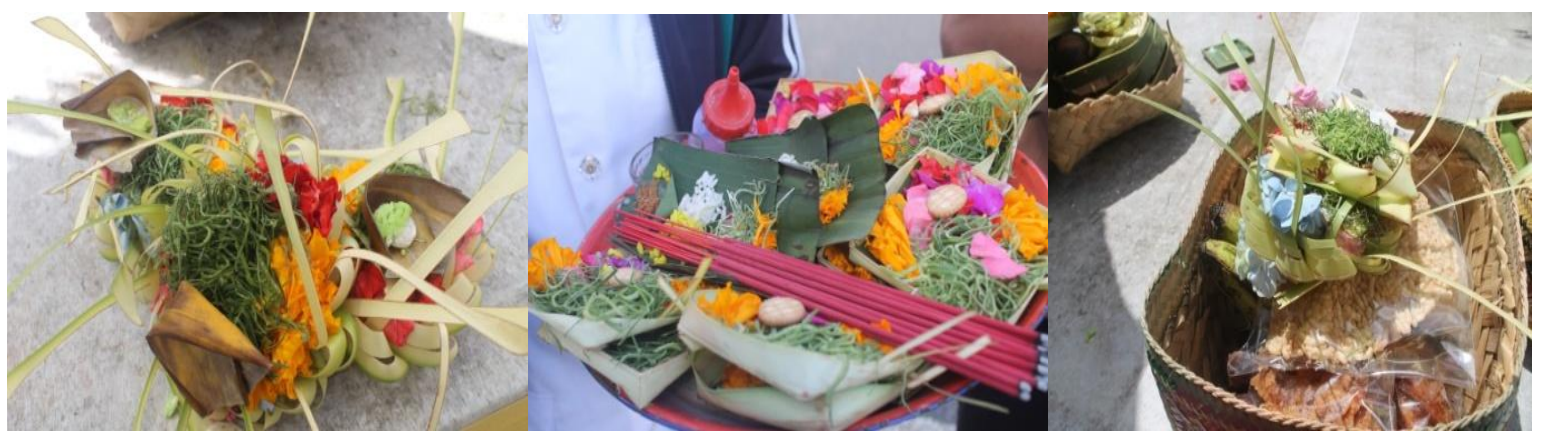

Gambar 3. Beberapa jenis bentuk Canang Sari.

Canang sari merupakan bentuk perwujudan rasa bhakti secara tulus ikhlas kehadapan Tuhan, yang menggambarkan pikiran yang halus, tenang, indah, menandakan rasa cinta kasih dan bhakti yang tulus (Wiana, 2007). Canang sari adalah sarana perlengkapan pokok saat ritual keagamaan Hindu-Bali, meskipun canang sari merupakan sarana yang paling sederhana, namun keberadaannya sangat penting (Radastami et al., 2018).

doli0.3I932/jpbio.v5iI.642 Ristanto et al


Persembahan canang sari secara teologis tidak sekedar mengundang Tri Mukti agar duduk di canang sari, tetapi sekaligus juga menyucikan, mewangikan dan menghormatinya agar Tri Mukti memberikannya berkah sesuai dengan apa yang ditetapkannya dalam suatu ritual (Andayana, 20I2). Pada canang sari, bunga disusun berdasarkan warnanya. Gagasan ini bisa dibenarkan mengingat agama Hindu mengenal simbol atau nyasa antara lain memakai warna (Puja, 2007; Bjonness, 2013; Suamba, 2004). Peletakan bunga harus mengikuti arah mata angin karena tiap arah mewakili dewa yang berbeda-beda sesuai dengan saktinya. Jenis tumbuhan yang paling sering digunakan antara lain yaitu Michelia alba yang berwarna putih disusun pada arah timur sebagai simbol Dewa Shiwa, Hibiscus rosa-sinensis yang berwarna merah disusun pada arah Selatan sebagai simbol Dewa Brahma, Michelia champaca yang berwarna kuning disusun pada arah Barat sebagai simbol Mahadewa, dan Impatiens balsamina yang berwarna biru (pengganti warna hitam) disusun pada arah utara sebagai simbol Dewa Wisnu. Selain itu, terdapat bunga rampai (irisan panda arum/Pandanus amaryllifolius) yang disusun di tengah sebagai simbol Panca Dewata.

\section{SIMPULAN}

Berdasarkan hasil penelitian yang telah dilakukan, diperoleh 9I spesies tumbuhan yang digunakan dalam ritual keagamaan Hindu-Bali. Bagian tumbuhan yang banyak digunakan dalam ritual keagamaan Hindu-Bali adalah bunga. Karakter morfologi warna menjadi perhatian dalam pemilihan tumbuhan yang digunakan. Bunga yang digunakan tidak spesifik, melainkan dapat digantikan oleh bunga dan bagian tumbuhan lainnya yang memiliki warna sama. Keterbatasan dalam penelitian ini yaitu waktu penelitian yang hanya 3 hari sehingga jumlah tumbuhan untuk ritual keagamaan Hindu-Bali yang didapatkan hanya 9I spesies. Untuk penelitian selanjutnya, dapat dipersiapkan rentang waktu yang lebih lama dan perluasan tempat penelitian agar diperoleh lebih banyak jumlah spesies tumbuhan yang digunakan dalam ritual keagamaan Hindu-Bali.

\section{UCAPAN TERIMAKASIH}

Ucapan terima kasih memuat apresiasi yang diberikan oleh penulis kepada semua pihak yang telah berperan dalam penelitian, yaitu kepada seluruh responden, pemuka agama dan ahli botani di kebun raya Bedugul Bali yang telah membantu memberikan informasi pada penelitian ini.

\section{REFERENSI}

Ambarani, D.P.L. (2016). Penempatan tanaman upakara sebagai elemen lunak taman pekarangan rumah ditinjau dari aspek filosofi budaya bali di kecamatan payangan, kabupaten gianyar, provinsi bali. (Skripsi tidak diterbitkan). Universitas Udayana.

Andayana, I.N.M. (2012). Arti dan fungsi banten aebagai sarana persembahyangan. Denpasar: Pustaka Bali Post.

Ayadnya, S.I.B \& Arinasa, I.B.K. (2004). Peranan wariga terhadap penggunaan tanaman upacara adat. seminar tumbuhan upacara agama hindu. UPT BKT Kebun Raya Eka Karya. Bali - LIPI.

Babaian, C., \& Twigg, P. (20I I). The power of plants: introducing ethnobotany \& biophilia into your biology class. The American Biology Teacher, 73(4), 217-22I. DOI: I0.1525/abt.20I I.73.4.6

Bjonness, R. (2013). Tantra yoga cinta dan pencerahan tuntutan personal, tradisi filsafat dan praktik tantra bagian a. Terjemahan AVA. Jakarta: Yayasan Ananda Marga Yoga.

Choudhary, K., Singh, M., \& Pillai, U. (2008). Ethnobotanical survey of rajasthan - an update. AmericanEurasian Journal of Botany, $I(2), 38-45$.

Dharma, I.D.P., Mudarsa, I.W., Peneng, I.N., \& Sumantera, I.W. (2002). Koleksi tanaman upacara adat bali kebun raya eka karya bali. Bali: UPT Balai Konservasi Tumbuhan Kebun Raya Eka Karya Bali-LIPI.

Dharmono. (2007). Kajian etnobotani tumbuhan jalukup (centella asiatica l.) di suku sayak bukit desa harataiI loksado. Media Konservasi, $4(2), \quad$ 7I-78. http:// citeseerx.ist.psu.edu/viewdoc/download?doi=IO.I.I.516.5799\&rep=repI\&type $=$ pdf

Ginting, E.Y. (2012). Studi etnobotani penggunaan tanaman obat tradisional etnis karo di desa jaranguda kecamatan merdeka kabupaten karo. (Disertasi tidak terbitkan), Universitas Negeri Medan, Medan. http://digilib.unimed.ac.id/I7228/

Harahap, L.J. Rahmadiana, V., Iman, F., Ristanto, R.H., \& Lisanti, E. (2009). Ethnoveterinary pharmacology: knowledge identification of sukarame society, carita, pandeglang, banten. Bioscience, 3(2), I87-196. DOI: 10.24036/0201932106354-0-00

Hidayat, S., Hikmat, A., \& Zuhud, E.A.M. (2010). Kajian etnobotani masyarakat kampung adat dukuh kabupaten garut, jawa barat. Media Konservasi, I5(3), I39-I5I. https://jurnal.ipb.ac.id/index.php/konservasi/article/view/I30I4 
Iskandar, J. (2016). Etnobiologi dan keragaman budaya di indonesia. Indonesian Journal of Anthropology, I(I), 2528-I569. DOI: I0.24I98/umbara.vIiI.9602

Lestari, W.S. (2004). Pemanfaatan tumbuhan untuk upacara agama hindu di beberapa wilayah di kabupaten gianyar. Prosiding Seminar Konservasi Tumbuhan Upacara Agama Hindu. 7 Oktober 2004, Bali, Indonesia, I(I), 273-278.

Lestari, P., Ristanto, R.H., \& Miarsyah, M. (2019a). Analysis of conceptual understanding of botany and metacognitive skill in pre-service biology teacher in Indonesia. Journal for the Education of Gifted Young Scientists, 7(2), I99-2I4. DOI: 10.17478/jegys.5I5978

Lestari, P., Ristanto, R. H., \& Miarsyah, M. (2019b). Metacognitive and conceptual understanding of pteridophytes: Development and validity testing of an integrated assessment tool. Indonesian Joumal of Biology Education, 2(I), I5-24. http://jurnal.untidar.ac.id/index.php/ijobe/article/view/I225

Malik, F. (2016). Peranan kebudayaan dalam pencitraan pariwisata bali. Jurnal Kepariwisataan Indonesia, II(I), 67-92. http://ejournal.kemenpar.go.id/index.php/jki/article/view/4

Martin, G.J. (1998). Etnobotani: sebuah manual pemeliharaan manusia dan tumbuhan. Edisi Bahasa MelayuTerjemahan Maryati Mohamed, Natural History Publications (Borneo) Sdn. Bhd. Kinabalu. Sabah. Malaysia.

Mesfin, K., Tekle, G., \& Tesfay, T. (2013). Ethnobotanical study of traditional medicinal plants used by indigenous people of gemad district, northern ethiopia. Journal of Medicinal Plants Studies, I(4), 32-37. http://www.plantsjournal.com/archives/2013/volI issue4/PartA/I I.I-IOI.pdf

Nala, N. (2004). Filosofis pemanfaatan dan keanekaragaman tanaman upacara agama hindu di bali. Dalam 'Prosiding Seminar Konservasi Tumbuhan Upacara Agama Hindu. UPT Balai Konservasi Tumbuhan Kebun Raya 'Eka Karya’ Bali.

Nasution, A., Chikmawati, T., Walujo, E.B., \& Zuhud, E. (2018). Ethnobotany of mandailing tribe in batang gadis national park. The Journal of Tropical Life Science, 8(I), 48-54. DOI: I0.I I594/jtls.08.01.09

Peneng, I.N. \& Sumantera, I.W. (2005). Pemanfaatan tebu dalam upacara adat di kabupaten tabanan, bali. Biodiversitas, 6(2), I38-I40. DOI: I0.I3057/biodiv/d0602I4

Puja, G. (2007). Wedaparikrama himpunan naskah mantra dan stotra teks asli bahasa sansakerta dan penjelasannya. Surabaya: Paramita.

Putri, R.I., Supriatna, J., \& Walujo, E.B. (20I4). Ethnobotanical study of plant resources in serangan island, bali. Asian Journal of Conservation Biology, 3(2), I35-I48. https://www.ajcb.in/journals/full_papers_dec_2014/AJCB-Vol3-No2-Putri\%20et\%20al.pdf

Radastami, K.A., Sinaga, R.M., \& Wakidi. (2018). Sesaji canang sari dalam ritual yajna masyarakat hindu-bali desa sidorejo kabupaten lampung timur. Bandar Lampung: FKIP Unila.

Saleh, S. (2017). Kerukunan umat beragama di denpasar bali. Al-Fikr, I7(I), II67-I75. http://journal.uinalauddin.ac.id/index.php/alfikr/article/view/2275

Sharma, U.K., \& Pegu, S. (20I I). Ethnobotany of religious and supernatural beliefs of the mising tribes of assam with special reference to the 'Dobur Uie'. I Ethnobiology Ethnomedicine 7(16), I-I3. DOI: I0.I I86/I746-4269-7-I6

Sholichah, L., \& Alfidhdhoh, D. (2020). Etnobotani tumbuhan liar sebagai sumber pangan di dusun mendiro, kecamatan wonosalam, jombang. Jurnal Ilmu Pertanian Indonesia, 25(I), III-II7. DOI: I0.I8343/jipi.25.I.I II

Steenis, V. (2008). Flora. Cetakan ke-I2. Jakarta: PT. Pradnya Paramita.

Suamba, I.B.P. (2004). OM pranava mantra. Denpasar. Dharmopadesa Pusat.

Sudarsana, I.B.P. (2010). Himpunanan tetanding upacara yadnya. Bali: Yayasan Dharma Acarya.

Sujarwo, W., \& Lestari, S.G. (2019). Studi etnobotani tumbuhan obat dan upacara adat Hindu di Bali. Buletin Kebun Raya, 2I(2), II7-I39. http://jurnal2.krbogor.lipi.go.id/index.php/buletin/article/view/44I

Surata, I.K., Gata,I.W., \& Sudiana, I.M. (20I5). Studi etnobotani tanaman upacara hindu bali sebagai upaya pelestarian kearifan lokal. Jurnal Kajian Bali, 05(2), 265-284. https://ojs.unud.ac.id/index.php/kajianbali/article/view/I6776

Suryadarma, I.G.P. (2008). Diktat kuliah etnobotani. Yogyakarta: Jurusan Pendidikan Biologi, FMIPA, Universitas Negeri Yogyakarta.

Tjitrosoepomo, G. (2018). Morfologi tumbuhan, cetakan keduapuluh satu. Yogyakarta: UGM Press.

Wiana, I.K. (2007). Tri hita karana, menurut konsep hindu. Surabaya: Paramita. 
Winarsih, E. (2015). Etnobotani tumbuhan obat oleh masyarakat kecamatan gerokgak kabupaten buleleng provinsi bali. (Tesis tidak diterbitkan). Fakultas Sains dan Teknologi, Universitas Islam Negeri Maulana Malik Ibrahim Malang. 